\title{
Evaluation of Pollock Liver Oil as a Supplement to Diets for Rainbow Trout*1
}

\author{
Takeshi WATANABE*2 and Toshio TAKEUCHI ${ }^{* 2}$
}

(Received March 17, 1976)

\begin{abstract}
The study was conducted preliminarily to examine the effect of dietary pollock liver oil on the growth of rainbow trout and to clarify the effective components in the oil by feeding the two principal fractions, nonsaponifiables and total fatty acids, separated from pollock liver oil. The results showed that pollock liver oil had a superior food value for fish growth and that its fatty acid fraction was the principal element, judging from the growth conditions and analytical data. In addition, a diet containing methyl linolenate in a quantity comparable to the total amount of $\omega 3$ fatty acids contained in pollock liver oil produced better growth, but the growth enhancing effect of the methyl linolenate was far less than that of the original pollock liver oil. It was thus postulated that $\omega 3$ highly unsaturated fatty acids in pollock liver oil may have a higher efficiency than that of linolenic acid in a manner similar to the relationship existing between linoleic and arachidonic acids in mammals.
\end{abstract}

Recent studies ${ }^{1-10)}$ on essential fatty acids (EFA) in fish have demonstrated that EFA requirements of fish differ considerably from species to species. Rainbow trout ${ }^{1-6)}$ require fatty acids of the linolenic family $(\omega 3)$ as EFA, whereas $\operatorname{carp}^{7,8)}$ and eel ${ }^{* 3}$ seem to require not only linolenic but also linoleic acids for good growth. On the other hand, these fatty acids were found to be nonessential for red sea bream of marine origin

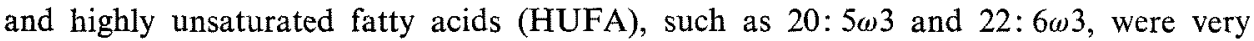
effective as EFA for the fish. ${ }^{9,10}$

It is of immediate interest that fish liver oils including the residual oil from molecular distillation of pollock liver oil for production of vitamin concentrates, were very effective in enhancing growth and improving feed conversion in all the species mentioned above which apparently require respectively different EFA. The mechanism of this growth stimulating effect is unknown but earlier workers suggested that it could be attributable to 1) fat-soluble vitamins $\mathrm{A}$ and $\mathrm{D},{ }^{11}{ }^{1 /}$ ) phospholipids, ${ }^{12}$ ) and 3) polyunsaturated fatty acids (PUFA), ${ }^{13,14}$ in cod liver oil. The recent results obtained on EFA requirement of fish, however, led us to postulate that the nutritive value of dietary cod liver oil in fish is probably due to PUFA, especially HUFA, in the fatty acid fraction. The purpose of this preliminary study was to examine the effect of dietary pollock liver oil on growth

${ }^{* 1}$ Studies on Nutritive Value of Dietary Lipids in Fish-VI.

*2 Laboratory of Fish Nutrition, Tokyo University of Fisheries, Konan 4, Minato-ku, Tokyo (渡辺 武. 竹内俊郎: 東京水産大学)

*: S. Arai, T. Watanabe, T. Takeuchi, and Y. Shimma: Oral presentation at the annual meeting of Japan. Soc. Sci. Fish., in Nagasaki, October, 1975. 
of rainbow trout fingerlings and to clarify the effective components in the oil by feeding two important fractions, nonsaponifiables and total fatty acids, separated from pollock liver oil. The results showed that the fatty acid fraction had almost the same effect as the orginal pollock liver oil both on growth of fish and feed conversion. We have made a further comparison of growth promoting effect between the total fatty acid fraction of pollock liver oil and linolenic acid by replacing a total amount of $\omega 3$ fatty acids in the pollock liver oil with a comparable amount of methyl linolenate.

\section{Materials and Methods}

The composition of the basal diet, preparation of diet, fish care and feeding were all the same as described previously. ${ }^{4)}$ The purity of methyl laurate (12:0) and methyl linolenate $(18: 3 \omega 3)$ by gas-liquid chromatography (GLC) was 97 and $93 \%$, respectively and weights were adjusted to incorporate exactly $100 \%$ of the desired component into diets. Soybean oil was purchased from a commercial source and corn oil and pollock liver oil were obtained from the Riken Vitamin Oils Co. Ltd. The proportions of these lipids in the diets used for Experiments I and II are shown in Table 1. The properties of the dietary lipids, and their component fatty acids, are shown in Tables 2 and 3 . The composition of dietary lipids used for Experiment III and the total amounts of $\omega 3$ fatty acids in the diets of each lot are shown in Table 4. The percentage of $\omega 3$ fatty acids in diets ranged from 0.05 (diet 11) and 0.84 (diet 14).

Fingerlings of rainbow trout Salmo gairdneri were used as the experimental animals. Eggs obtained from the Ohizumi Experimental Station of our university were hatched in our laboratory and the fry were kept on a commercial diet for three months. They were then divided into lots of 50 fish each, four in Experiment I, five in Experiment II and nine in Experiment III, and fed diet 3 (the control diet) for 2 weeks before the initiation

Table 1. Compositions of dietary lipids

\begin{tabular}{cl}
\hline Diet no. & \multicolumn{1}{c}{ Dietary lipid } \\
\hline Experiment I & 5\% Soybean oil \\
1 & $5 \%$ Corn oil \\
2 & $3 \%$ Soybean oil $+2 \%$ Pollock liver oil \\
3 & $3 \%$ Corn oil $+2 \%$ Pollock liver oil \\
4 & $3.04 \% 12: 0^{*}+1.96 \%$ Methyl esters of pollock liver oil \\
Experiment II & $4.96 \% 12: 0^{*}+0.04 \%$ Nonsaponifiables of pollock liver oil \\
5 & $3.00 \% 12: 0^{*}+\{1.96 \%$ Methyl esters \\
6 & $40.04 \%$ Nonsaponifiables of pollock liver oil \\
7 & $4.99 \% 12: 0^{*}+0.01 \%$ Lecithin \\
8 & $4.95 \% 12: 0^{*}+0.05 \%$ Lecithin \\
9
\end{tabular}

\footnotetext{
* Methylester.
} 
Table 2. Characteristics of dietary lipids

\begin{tabular}{lccc}
\hline & Soybean oil & Corn oil & Pollock liver oil \\
\hline Nonsaponifiables $(\%)$ & 0.2 & 0.8 & 2.0 \\
Acid value & 0.08 & 0.08 & 0.36 \\
Saponification value & 162.7 & 163.1 & 155.7 \\
Iodine value & 113.0 & 101.5 & 129.5 \\
Peroxide value & 5.3 & 0.9 & 13.5 \\
Vitamin A $(\mathrm{IU} / \mathrm{g})$ & 2.5 & 0.7 & 1790.0 \\
$\alpha$-Tocopherol $(\mu \mathrm{g} / \mathrm{g})$ & 250 & 650 & 70 \\
\hline
\end{tabular}

Table 3. Fatty acid composition of dietary lipids $(\%)$

\begin{tabular}{|c|c|c|c|c|c|c|}
\hline Fatty acid & $\begin{array}{l}\text { Soybean } \\
\text { oil }\end{array}$ & Corn oil & $\begin{array}{l}3 \% \text { Soybean oil } \\
2 \% \text { Pollock liver } \\
\text { oil }\end{array}$ & $\begin{array}{c}3 \% \text { Corn oil } \\
2 \% \text { Pollock liver } \\
\text { oil }\end{array}$ & $\begin{array}{c}\text { Pollock } \\
\text { liver } \\
\text { oil }\end{array}$ & Lecithin \\
\hline $14: 0$ & 0.1 & & 2.1 & 1.9 & 3.4 & \\
\hline $16: 0$ & 11.1 & 12.9 & 10.1 & 12.2 & 13.5 & 28,4 \\
\hline $16: 1$ & & & 3.4 & 3.9 & 8.8 & 1.5 \\
\hline $18: 0$ & 4.7 & 2.7 & 3.7 & 2.8 & 1.7 & 19.6 \\
\hline $18: 1$ & 23.6 & 39.6 & 22.9 & 33.4 & 20.1 & 28.3 \\
\hline $18: 2 \omega 6$ & 52.8 & 43.6 & 34.7 & 29.2 & 1.0 & 14.9 \\
\hline $18: 3 \omega 3$ & 7.7 & 0.9 & 4.6 & 1.6 & 0.3 & \\
\hline $\left.\begin{array}{l}18: 4 \omega 3 \\
20: 1\end{array}\right\}$ & & & 6.7 & 6.9 & 18.8 & \\
\hline $22: 1$ & & & 5.0 & 5.0 & 12.7 & \\
\hline $20: 5 \omega 3$ & & & 3.9 & 3.9 & 9.9 & \\
\hline $22: 6 \omega 3$ & & & 1.8 & 1.8 & 3.8 & 2.7 \\
\hline$\sum \omega 6$ & 52.8 & 43.6 & 34.7 & 29.2 & 1.7 & 14.9 \\
\hline$\sum \quad \omega 3$ & 7.7 & 0.9 & 11.5 & 8.3 & 17.7 & 2.7 \\
\hline
\end{tabular}

Table 4. Compositions of dietary lipids and the total amount of $\omega 3$ fatty acids in diets for Experiment III

\begin{tabular}{clc}
\hline Diet no. & Dietary lipid & Total $\omega 3 \%$ \\
\hline 10 & $5 \%$ Soybean oil & 0.39 \\
11 & $5 \%$ Corn oil & 0.05 \\
12 & $3 \%$ Soybean oil $+2 \%$ Pollock liver oil & 0.65 \\
13 & $3 \%$ Corn oil $+2 \%$ Pollock liver oil & 0.45 \\
14 & $4.5 \%$ Soybean oil $+0.5 \% 18: 3 \omega 3^{*}$ & 0.84 \\
15 & $4.5 \%$ Corn oil $+0.5 \% 18: 3 \omega 3^{*}$ & 0.54 \\
16 & $3 \%$ Soybean oil $+2 \%$ Methyl esters of pollock liver oil & 0.65 \\
17 & $3 \%$ Soybean oil $+\{1.96 \%$ Methyl esters $0.04 \%$ Nonsaponifiables of pollock liver oil & 0.65 \\
18 & $3 \%$ Methyl esters of soybean oil $+2 \%$ Methyl esters of pollock liver oil & 0.65 \\
\hline
\end{tabular}

* Methylester.

of feeding trials in order to accustom the fish to casein diets.

In Experiment I four test diets were prepared to test the effect of supplement of pollock liver oil on growth of the fish, by respectively replacing each two-fifths of the soybean oil and corn oil in diets 1 and 2, with an equal amount of pollock liver oil. 
Diet 3 containing $3 \%$ soybean oil and $2 \%$ pollock liver oil was arranged as a control group as described previously. ${ }^{4}$. The feeding period was 14 weeks. For Experiment II pollock liver oil was separated into the two basic fractions, nonsaponifiables and fatty acid mixture, and then each fraction was fed to rainbow trout at a level equivalent to the addition of $2 \%$ pollock liver oil for 8 weeks. In addition, lecithin was fed to fish at 0.01 and $0.05 \%$ levels in diets in order to examine the effect of phospholipids on growth and feed conversion.

In Experiment III, diets 10 to 13 and 16 to 17 were prepared to reexamine the growth enhancing effect of pollock liver oil and of its fatty acid fraction, observed in Experiments I and II. Diet 12 was a control group. Diets 14 and 15, supplemented with $0.5 \% 18: 3 \omega 3$, were modification of diets 12 and 13 in which methyl linolenate comparable in quantity to a total amount of $\omega 3$ fatty acids contained in $2 \%$ pollock liver oil was added to compare the effect of the pollock liver oil fatty acid fraction with that of linolenic acid on growth and fatty acid composition of rainbow trout. Diet 18 was a modification of the control diet (diet 12) in which both soybean oil and pollock liver oil were added in the form of methyl esters to compare the difference in growth effect between a natural oil and the methyl esters of its fatty acids. The feeding period was 14 weeks.

Pollock liver oil was saponified by the usual method, and the nonsaponifiables were extracted with diethyl ether. The total fatty acids recovered from the oil were methylated with boron trifluoride in methanol. ${ }^{16)}$ Egg yolk lecitin purchased from the Merck Industry Co. Ltd., was purified three times by precipitation with acetone. The procedures for separation of polar and nonpolar lipids with a gel column, isolation of

Table 5. GLC operating conditions for the determination of fatty acid and triglyceride compositions

\begin{tabular}{|c|c|c|}
\hline & Fatty acid & Triglyceride \\
\hline Apparatus & \multicolumn{2}{|c|}{$\begin{array}{l}\text { Shimadzu gas chromatograph GC-6A with a hydrogen } \\
\text { flame ionization detector }\end{array}$} \\
\hline Column & Glass tube $2.0 \mathrm{~m} \times 3 \mathrm{~mm} \phi$ & Glass tube $0.5 \mathrm{~m} \times 3 \mathrm{~mm} \phi$ \\
\hline Packing & $\begin{array}{l}15 \% \text { DEGS on } 80 / 100 \text { mesh } \\
\text { Shimalte }\end{array}$ & $\begin{array}{l}1 \% \text { OV }-1 \text { on } 60 / 80 \text { mesh } \\
\text { Chromosorb } W\end{array}$ \\
\hline Carrier gas & Nitrogen & Nitrogen \\
\hline \multicolumn{3}{|l|}{ Flow rate } \\
\hline Nitrogen & $2.2 \mathrm{~kg} / \mathrm{cm}^{2}$ & $1.2 \mathrm{~kg} / \mathrm{cm}^{2}$ \\
\hline Hydrogen & $0.8 \mathrm{~kg} / \mathrm{cm}^{2}$ & $0.8 \mathrm{~kg} / \mathrm{cm}^{2}$ \\
\hline Air & $1.0 \mathrm{~kg} / \mathrm{cm}^{2}$ & $1.0 \mathrm{~kg} / \mathrm{cm}^{2}$ \\
\hline \multicolumn{3}{|l|}{ Temperature } \\
\hline Detector & $220^{\circ} \mathrm{C}$ & $350^{\circ} \mathrm{C}$ \\
\hline Injection port & $220^{\circ} \mathrm{C}$ & $350^{\circ} \mathrm{C}$ \\
\hline Column & Isothermal $190^{\circ} \mathrm{C}$ & $\begin{array}{l}\text { Programm } 200^{\circ}-340^{\circ} \mathrm{C} \\
\text { at } 4^{\circ} \mathrm{C} / \mathrm{min}\end{array}$ \\
\hline
\end{tabular}


triglycerides from the nonpolar lipids, and determination of vitamin $\mathrm{A}$ and $\mathrm{E}$ contents were all the same as those described in the previous papers. ${ }^{6,17}$ GLC operating conditions for determination of fatty acids and for the direct analysis of triglycerides are summarized in Table 5.

At the end of the feeding trials, ten fish were taken from each lot and pooled for determination of moisture, protein and lipids. The remainder of fish was used for determination of fatty acid and triglyceride compositions and for analyses of vitamin $\mathrm{A}$ and $\alpha$-tocopherol contents in the liver and muscle.

\section{Results and Discussion}

Results of feeding experiment The effect of dietary lipids on mean weight gain, percent gain, feed conversion, hepatosomatic index (the percentage of liver weight to body weight) and mortality are summarized in Table 6 and Figs. 1 to 3.

Table 6. Results of feeding experiments for 14 weeks in Experiments I and III, and for 8 weeks in Experiment II

\begin{tabular}{|c|c|c|c|c|c|c|}
\hline \multirow{2}{*}{ Diet no. } & \multicolumn{2}{|c|}{ Av body wt (g) } & \multirow{2}{*}{$\begin{array}{l}\text { Percent } \\
\text { gain }\end{array}$} & \multirow{2}{*}{ Feed $_{\text {conversion }}^{* 1}$} & \multirow{2}{*}{$\begin{array}{l}\text { Hepato- } \\
\text { somatic } \\
\text { index }\end{array}$} & \multirow{2}{*}{$\begin{array}{c}\text { Mortality } \\
(\%)\end{array}$} \\
\hline & Initial & Final & & & & \\
\hline \multicolumn{7}{|c|}{ Experiment I } \\
\hline 1 & 1.3 & 12.6 & 869 & 1.00 & 1.5 & 2 \\
\hline 2 & 1.2 & 10.0 & 733 & 0.98 & 1.4 & 2 \\
\hline 3 & 1.2 & 14.8 & 1133 & 1.08 & 1.4 & 2 \\
\hline 4 & 1.2 & 14.6 & 1117 & 1.11 & 1.4 & 2 \\
\hline \multicolumn{7}{|c|}{ Experiment II } \\
\hline 5 & 1.5 & 6.4 & 327 & 1.07 & 1.5 & 2 \\
\hline 6 & 1.5 & 3.3 & 120 & 0.79 & 1.7 & 24 \\
\hline 7 & 1.5 & 6.5 & 333 & 1.10 & 1.5 & 2 \\
\hline 8 & 1.5 & 3.0 & 100 & 0.83 & 1.7 & 24 \\
\hline 9 & 1.5 & 3.3 & 120 & 0.84 & 1.8 & 29 \\
\hline \multicolumn{7}{|c|}{ Experiment III } \\
\hline 10 & 1.1 & 11.7 & 964 & 1.14 & 1.2 & 0 \\
\hline 11 & 1.2 & 8.2 & 583 & 1.03 & 1.4 & 0 \\
\hline 12 & 1.1 & 15.5 & 1309 & 1.26 & 1,4 & 0 \\
\hline 13 & 1.2 & 15.2 & 1167 & 1.20 & 1.3 & 0 \\
\hline 14 & 1.2 & 12.9 & 975 & 1.19 & 1.2 & 0 \\
\hline 15 & 1.1 & 10.6 & 864 & 1.15 & 1.2 & 0 \\
\hline 16 & 1.2 & 14.0 & 1067 & 1.24 & 1.2 & 0 \\
\hline 17 & 1.1 & 14.4 & 1209 & 1.24 & 1.1 & 0 \\
\hline 18 & 1.1 & 14.0 & 1173 & 1.16 & 1.3 & 0 \\
\hline
\end{tabular}

*1 Feed conversion is defined as grams of weight grained per grams of dry feed consumed.

The growth rate was low in fish on diets containing $5 \%$ soybean oil (diet 1 ) or $5 \%$ corn oil (diet 2) as the sole lipid source, but was better in fish on diet 1 than those on diet 2. This may be due to the effect of linolenic acid contained at about $8 \%$ in soybean oil $(0.39 \%$ in diet) as shown in Table 3 . There was no significant difference in hepato- 


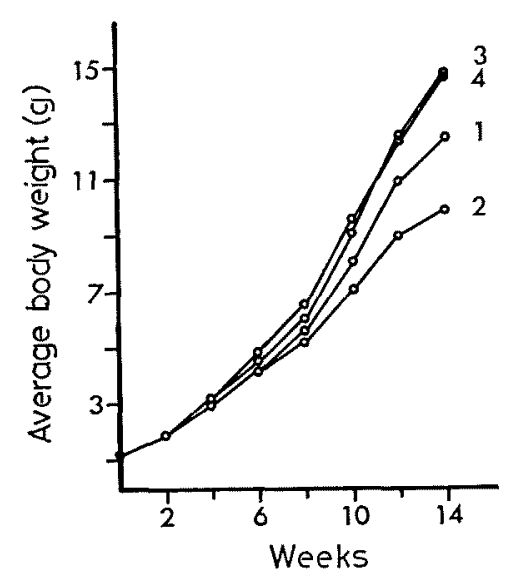

Fig. 1

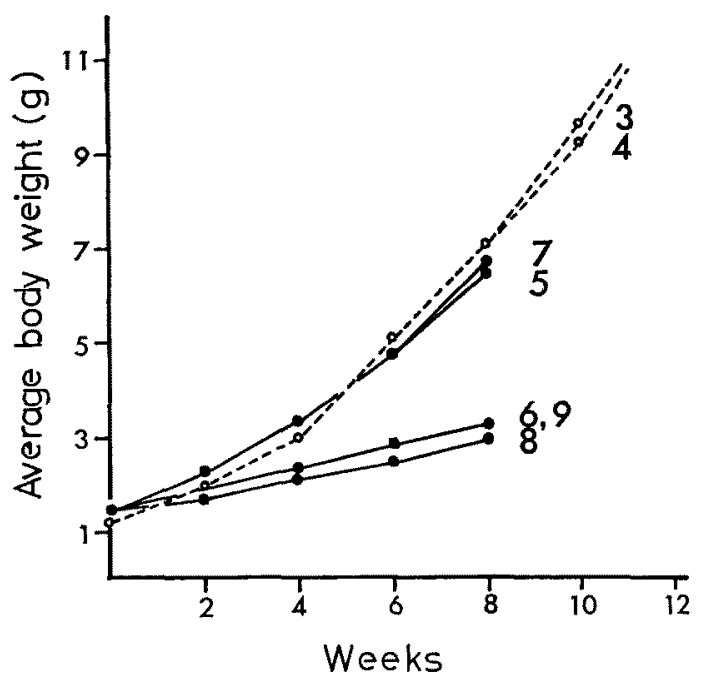

Fig. 2

Fig. 1. Effect of dietary pollock liver oil on growth rate of rainbow trout in Experiment $\mathbf{I}$. Curves 1 and 3 , the soybean oil diets containing 0 and $2 \%$ pollock liver oil, respectively. Curves 2 and 4 , the corn oil diets containing 0 and $2 \%$ pollock liver oil, respectively.

Fig. 2. Effects of the fatty acid fraction and the nonsaponifiable fraction of pollock liver oil on growth rate of rainbow trout in Experiment II.

Curves $5,6,7,8$ and 9 , the methyl laurate diets containing respectively $1.96 \%$ methyl esters of pollock liver oil, $0.04 \%$ nonsaponifiable fraction, $1.96 \%$ methyl esters plus $0.04 \%$ nonsaponifiable fraction of pollock liver oil, $0.01 \%$ lecithin and $0.05 \%$ lecithin.

somatic index among experimental groups, since both linoleic and linolenic acids in soybean oil and corn oil have a preventive effect against enlargement of livers in rainbow trout. ${ }^{6)}$ Mortality was low in all the lots throughout the feeding trial period. The replacement of each two-fifths of the soybean oil and corn oil by pollock liver oil resulted in improvement of growth rate, as was observed in previous work with rainbow trout ${ }^{5,6}$ ) and carp. ${ }^{7,8)}$ The same kind of stimulatory effect of cod liver oil has also been observed in eel, ${ }^{18)}$ red sea bream, ${ }^{197}$ yellowtail ${ }^{20)}$ and oysters. ${ }^{21)}$ For example, ARAI et al. reported that in test diets for eel, the mixed oil consisting of corn oil and cod liver oil in a proportion, $2: 1$, was the most favorable fat source. In the case of yellowtail, cod liver oil performed effectively both for rapid growth and in maintaining healthy physiological conditions. These previous findings are supported by our present results.

As shown in Table 6 and Fig. 2, the growth and feed conversion were significantly low in fish fed a diet containing the nonsaponifiable fraction of pollock liver oil (diet 6 ) and diets containing lecithin (diets 8 and 9), and the mortality of these groups was as high as $24-29 \%$. On the other hand, the diets containing the pollock liver oil fatty acid fraction as methyl esters resulted in good growth rate and feed conversion as was com- 


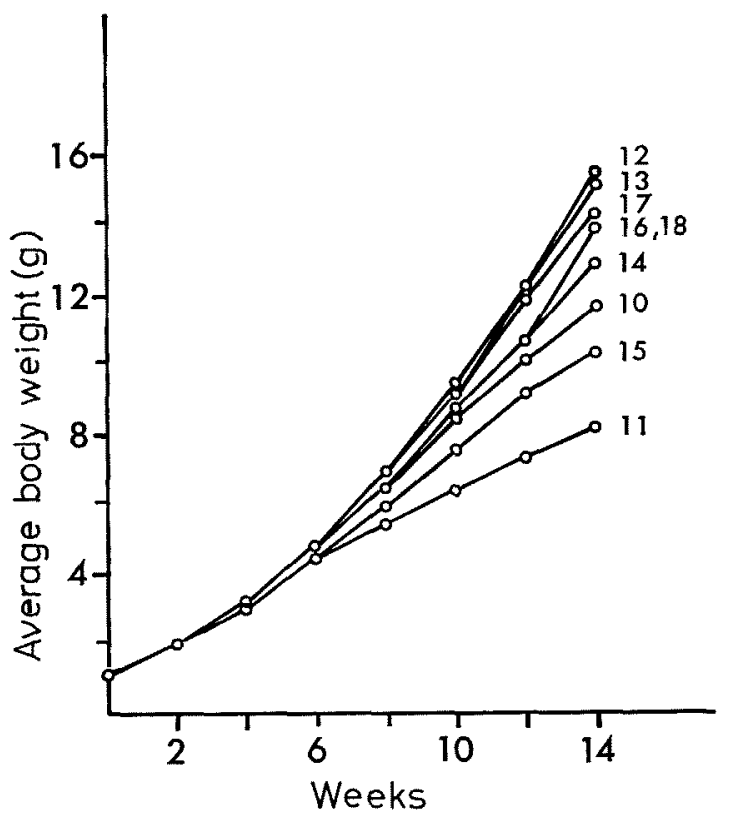

Fig. 3. Effect of dietary lipids on growth rate of rainbow trout in Experiment III.

Curves $10,12,14,16$ and 17 , the soybean oil diets containing $0.2 \%$ pollock liver oil, $0.5 \%$ methyl linolenate, $2 \%$ methyl esters of pollock liver oil and the methyl esters plus nonsaponifiable fraction, respectively. Curves 11,13 and 15 , the corn oil diets containing 0 and $2 \%$ pollock liver oil, and $0.5 \%$ methyl linolenate. Curve $18,3 \%$ methyl esters of soybean oil plus $2 \%$ methyl esters of pollock liver oil.

parable with those of the control group in Experiment 1 . However, addition of the nonsaponifiable fraction to the fatty acid fraction did not result in any further improvement in growth and feed conversion at the end of the feeding period of 8 weeks. The addition of lecithin at 0.01 and $0.05 \%$ levels to methyl laurate exerted no beneficial effect on growth conditions and resulted in EFA-deficiency.

In Experiment III there was neither mortality nor significant difference in hepatosomatic index among experimental groups. As shown in Table 6 and Fig. 3, the result obtained in fish fed on diets 10 to 13 which were arranged for reexamination of Experiment I are very similar to those in Experiment I, indicating assuredly the excellent growth promoting effect of pollock liver oil.

Diet 15 , a modification of diet 13 in which an approximately equal amount of methyl linolenate as a total amount of $\omega 3$ fatty acids contained in $2 \%$ pollock liver oil was added, produced a better growth, but the growth enhancing effect of methyl linolenate was far less than that of the addition of $2 \%$ pollock liver oil, in spite of the fact that the percentage of $\omega 3$ fatty acids in diet 15 was higher than that of diet 13 as shown in Table 4. A similar result was obtained in the case of diet 14, a modification of the 
control diet (diet 12). This fact may indicate that HUFA in the pollock liver oil had an EFA value higher than linolenic acid.

Diets 16 and 17 , containing respectively either the pollock liver oil fatty acid fraction or the fatty acid fraction plus the nonsaponifiables, gave good growth and feed conversion to a level almost the same as those of the fish fed the intact pollock liver oil (diets 12 and 13). In the previous feeding trial for 8 weeks the additive effect of the nonsaponifiables was not recognized, but the addition of the nonsaponifiable fraction to diet 16 resulted in a slight increase in growth in a 14-week feeding period.

Excellent fish growth was also obtained with diet 18 , a modification of diet 12 in which both soybean oil and pollock liver oil were supplemented in the form of methyl esters, indicating that methyl esters as dietary lipids ${ }^{3,5-7)}$ had no adverse effect upon fish growth.

Proximate compositions of experimental fish The analytical data on the whole bodies, muscle and livers of fish in Experiments I, II and III at the end of feeding trials are summarized in Table 7.

In the fish receiving 5\% soybean oil (diet 1 ) and $5 \%$ corn oil (diet 2), a relatively high water content reflected the low protein level in the whole bodies and muscle, but the difference was not as significant as that of fish fed diets low in EFA in Experiment II.

Table 7. Proximate compositions of the experimental rainbow trout after 14 weeks in Experiments $\mathrm{I}$ and III, and after 8 weeks in Experiment II (\%)

\begin{tabular}{|c|c|c|c|c|c|c|c|}
\hline \multirow{2}{*}{ Diet no. } & \multicolumn{3}{|c|}{ Whole body } & \multicolumn{3}{|c|}{ Muscle } & \multirow{2}{*}{$\frac{\text { Liver }}{\text { Fat }}$} \\
\hline & Moisture & Protein & Fat & Moisture & Protein & Fat & \\
\hline \multicolumn{8}{|c|}{ Experiment I } \\
\hline 1 & 76.2 & 14.8 & 7.3 & 77.5 & 19.0 & 3.6 & 6.9 \\
\hline 2 & 75.7 & 14.8 & 7.3 & 77.6 & 19.0 & 2.7 & 7.1 \\
\hline 3 & 73.6 & 15.8 & 8.5 & 76.5 & 19.6 & 3.0 & 5.5 \\
\hline 4 & 74.2 & 16.2 & 7.5 & 76.0 & 20.1 & 3.2 & 5.5 \\
\hline \multicolumn{8}{|c|}{ Experiment II } \\
\hline 5 & 75.2 & 15.9 & 7.0 & 77.6 & 19.4 & 3.0 & 4.2 \\
\hline 6 & 78.9 & 14.2 & 3.7 & 79.7 & 18.7 & 1.6 & 5.3 \\
\hline 7 & 75.3 & 15.6 & 7.4 & 77.5 & 19.2 & 2.7 & 3.9 \\
\hline 8 & 80.4 & 14.1 & 2.9 & 79.7 & 18.1 & 1.9 & 5.1 \\
\hline 9 & 81.2 & 13.9 & 2.7 & 79.7 & 18.3 & 1.8 & 4.9 \\
\hline \multicolumn{8}{|c|}{ Experiment III } \\
\hline 10 & 73.7 & 16.2 & 6.9 & 76.4 & 19.5 & 3.2 & 5.4 \\
\hline 11 & 75.0 & 16.1 & 6.7 & 77.5 & 18.7 & 2.9 & 7.5 \\
\hline 12 & 73.3 & 16.1 & 7.6 & 76.4 & 19.5 & 3.3 & 5.9 \\
\hline 13 & 73.1 & 16.7 & 7.6 & 76.5 & 20.0 & 3.1 & 5.9 \\
\hline 14 & 73.6 & 15.9 & 7.4 & 76.7 & 19.7 & 3.1 & 5.1 \\
\hline 15 & 74.6 & 16.4 & 7.1 & 76.8 & 19.7 & 3.1 & 5.1 \\
\hline 16 & 73.7 & 15.9 & 7.7 & 77.1 & 19.5 & 3.3 & 5.8 \\
\hline 17 & 72.7 & 16.9 & 8.2 & 76.6 & 20.0 & 3.2 & 5.2 \\
\hline 18 & 74.4 & 16.0 & 7.0 & 77.2 & 19.3 & 3.1 & 5.4 \\
\hline
\end{tabular}


In addition, these fish showed a high content of liver lipids, which is one of the characteristics of $\omega 3$ fatty acid deficiency in rainbow trout. These results agree well with the previous report. $^{6}$ Replacing soybean oil and corn oil with a comparable amount of pollock liver oil in diets 3 and 4 effectively lowered both the body water and liver lipid contents, suggesting that the $\omega 3$ acids are EFA.

Although the feeding trial period was 8 weeks in Experiment II, the fish receiving a diet supplemented with the nonsaponifiable fraction of pollock liver oil (diet 6) and diets containing lecithin (diets 8 and 9) showed apparent EFA deficiency symptoms, based upon the analytical data of a significantly high percentage of water content reflecting low levels of protein and lipids. This was recognized in both the whole bodies and muscle and supported by observation on the livers of these fish where a high lipid content was found. These results are in good agreement with those obtained in fish fed the EFAdeficient diet in the previous work. ${ }^{6}$ ) On the other hand, these was no difference in proximate compositions between two groups which received diets containing respectively the fatty acid fraction (diet 5) and the fraction plus the nonsaponifiables (diet 7), and these diets produced similar results to those obtained in the control group in Experiment I, even though they showed slight variations in analytical values due to the difference of the feeding period.

In Experiment III, the results obtained in fish fed on diets 10 to 13, the reexamination of Experiment I, showed almost the same tendency to those in Experiment I. In other groups, in general, no significant difference was recognized as due to dietary lipids.

Lipid compositions As reported previously, ${ }^{5,0)}$ the dietary levels of $\omega 3$ fatty acids exert some effect on the ratio of polar to nonpolar lipids and a similar result was obtained in Experiments I to III. The lipid composition of the liver obtained in Experiment III is presented in Table 8 and Fig. 4. Fig. 4 shows a negative linear relationship between percent lipid in the liver and percent polar lipid in the liver lipids. The percent polar lipid in the liver lipids decreased as the percent lipid in the liver increased, but as shown

Table 8. Effect of dietary lipids on lipid compositions of the liver

\begin{tabular}{lcccccc}
\hline & \multicolumn{3}{c}{$\%$} & & \multicolumn{2}{c}{$\%$ in Liver lipid } \\
\cline { 2 - 4 } \cline { 6 - 6 } Diet no in & Total & Polar & Nonpolar & & Polar & Nonpolar \\
\hline 10 & 5.4 & 2.8 & 2.6 & & 51.6 & 48.4 \\
11 & 7.5 & 2.7 & 4.8 & & 36.2 & 63.8 \\
12 & 5.9 & 2.9 & 3.0 & & 48.3 & 51.7 \\
13 & 5.9 & 2.9 & 3.0 & & 48.9 & 51.1 \\
14 & 5.1 & 3.0 & 2.1 & & 57.9 & 42.1 \\
15 & 5.1 & 2.9 & 2.2 & & 56.0 & 44.0 \\
16 & 5.8 & 2.6 & 3.2 & & 45.2 & 54.8 \\
17 & 5.2 & 2.8 & 2.4 & & 54.3 & 45.7 \\
18 & 5.4 & 2.6 & 2.8 & & 48.7 & 51.3 \\
\hline
\end{tabular}




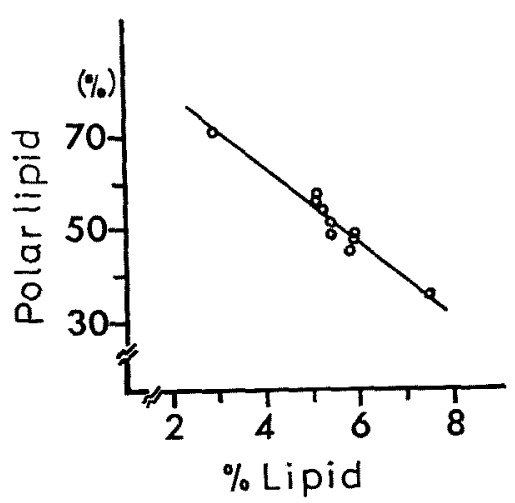

Fig. 4. A negative linear relationship between percent lipid in the liver and percent polar lipid in the liver lipids.

in Table 8, the percent polar lipid in the liver was relatively constant, and the percentage of nonpolar lipid was altered considerably as the lipid content was altered by the EFAdeficiency. The fish fed the $5 \%$ corn oil diet showed the lowest ratio of polar lipids in the liver lipids, which was one of the characteristics of rainbow trout receiving insufficient amounts of $\omega 3$ fatty acids, ${ }^{3,5,6)}$ indicating an accumulation of nonpolar lipids in the liver. In other experimental groups, there was no significant difference in lipid composition of the liver due to dietary lipids.

Fatty acid composition Fatty acid compositions of the triglyceride and polar lipid fractions from the livers of fish in Experiment III are summarized in Tables 9 and 10, respectively. There was no significant difference in fatty acid compositions of triglyceride fraction, whereas the fatty acids in polar lipids reflected the incorporation of different dietary lipids. When comparing the triglyceride

Table 9. Fatty acid composition of the triglyceride fractions from the livers of fish in Experiment III (area \%)

\begin{tabular}{|c|c|c|c|c|c|c|c|c|c|}
\hline $\begin{array}{l}\text { Fatty } \\
\text { acid }\end{array}$ & 10 & 11 & 12 & 13 & $\begin{array}{c}\text { Diet no. } \\
14\end{array}$ & 15 & 16 & 17 & 18 \\
\hline $12: 0$ & 0.4 & 0.1 & 0.2 & 0.1 & 0.3 & 0.2 & 0.2 & 0.1 & 0.2 \\
\hline $14: 0$ & 2.2 & 1.6 & 2.4 & 2.1 & 1.9 & 1.9 & 1.7 & 1.5 & 2.0 \\
\hline $16: 0$ & 16.2 & 11.1 & 12.7 & 11.5 & 12.5 & 10.6 & 13.2 & 10.9 & 12.9 \\
\hline $16: 1$ & 7.4 & 8.3 & 10.6 & 9.8 & 7.2 & 6.9 & 8.0 & 8.5 & 9.4 \\
\hline $18: 0$ & 6.7 & 6.5 & 4.8 & 4.9 & 6.2 & 5.7 & 6.0 & 5.0 & 5.6 \\
\hline $18: 1$ & 43.5 & 55.2 & 53.3 & 55.9 & 46.8 & 54.4 & 53.0 & 53.0 & 54.5 \\
\hline $18: 2 \omega 6$ & 9.1 & 5.7 & 5.2 & 4.3 & 11.1 & 6.7 & 6.0 & 7.8 & 5.4 \\
\hline $18: 3 \omega 6$ & 0.6 & 0.4 & 0.2 & 0.2 & 0.7 & 0.3 & 0.4 & 0.5 & 0.2 \\
\hline $18: 3 \omega 3$ & 0.4 & tr & 0.3 & 0.1 & 1.6 & 0.5 & 0.4 & 0.6 & 0.2 \\
\hline $18: 4 \omega 3$ & 0.3 & 0.2 & 0.1 & 0.1 & 0.4 & 0.2 & 0.2 & 0.2 & 0.2 \\
\hline $20: 1$ & 5.1 & 5.7 & 4.6 & 5.7 & 4.5 & 6.6 & 6.0 & 5.8 & 4.9 \\
\hline $20: 2 \omega 9$ & 1.4 & 1.4 & 1.2 & 1.5 & 1.1 & 1.5 & 1.4 & 1.8 & 1.2 \\
\hline $20: 2 \omega 6$ & 1.6 & 1.4 & 0.8 & 0.9 & 1.5 & 1.5 & 0.8 & 1.4 & 0.9 \\
\hline $20: 3 \omega 9$ & 0.2 & 0.4 & 0.4 & 0.4 & $\mathrm{tr}$ & 0.2 & tr & $\operatorname{tr}$ & $\operatorname{tr}$ \\
\hline $20: 3 \omega 6$ & 1.5 & 0.5 & 0.5 & 0.5 & 1.2 & 0.7 & 0.6 & 0.7 & 0.6 \\
\hline $20: 4 \omega 6$ & 1.2 & 0.6 & 0.5 & 0.4 & 1.1 & 0.7 & 0.5 & 0.4 & 0.5 \\
\hline $20: 5 \omega^{3}$ & 0.3 & 0.3 & 0.5 & tr & $\operatorname{tr}$ & 0.3 & 0.5 & 0.6 & 0.3 \\
\hline $22: 5 \omega 6$ & 0.5 & 0.4 & 0.2 & $\operatorname{tr}$ & 0.4 & 0.3 & tr & tr & $\operatorname{tr}$ \\
\hline $22: 6 \omega 3$ & 0.4 & $\operatorname{tr}$ & 1.4 & 1.0 & 1.1 & 0.5 & 0.8 & 1.2 & 0.8 \\
\hline$\sum \omega 6$ & 14.7 & 9.0 & 7.3 & 6.2 & 16.0 & 19.2 & 8.1 & 10.7 & 7.6 \\
\hline$\sum \omega 3$ & 1.4 & 0.5 & 2.2 & 1.2 & 3.1 & 1.5 & 1.8 & 2.5 & 1.6 \\
\hline
\end{tabular}


fraction with polar lipid fraction, the percentage of 18:1 was considerably higher in the

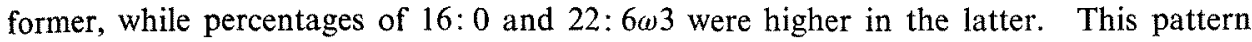
was also observed in carp. ${ }^{8}$. Feeding the diet containing $5 \%$ corn oil resulted in an increase of 16:1 and 18:1 monoethylenic fatty acids, characteristically observed in rainbow trout fed a diet low in $\omega 3$ fatty acids.

Table 10. Fatty acid compositions of polar lipid fraction from the livers of the experimental fish for 14 weeks in Experiment III (area \%)

\begin{tabular}{|c|c|c|c|c|c|c|c|c|c|}
\hline $\begin{array}{l}\text { Fatty } \\
\text { acid }\end{array}$ & 10 & 11 & 12 & 13 & $\begin{array}{c}\text { Diet no. } \\
14\end{array}$ & 15 & 16 & 17 & 18 \\
\hline $14: 0$ & 1.3 & 2.2 & 2.1 & 1.3 & 1.1 & 1.3 & 1.4 & 1.8 & 1.4 \\
\hline $16: 0$ & 21.8 & 19.2 & 23.2 & 20.8 & 20.4 & 20.9 & 19.2 & 25.4 & 21.4 \\
\hline $16: 1$ & 5.4 & 10.7 & 6.4 & 5.3 & 4.2 & 5.3 & 5.2 & 6.5 & 6.0 \\
\hline 18: 0 & 8.4 & 5.0 & 6.9 & 7.2 & 8.7 & 7.2 & 6.6 & 7.5 & 7.6 \\
\hline $18: 1$ & 16.7 & 26.7 & 21.4 & 20.4 & 16.2 & 19.1 & 18.8 & 18.2 & 17.8 \\
\hline $18: 2 \omega 6$ & 6.0 & 5.9 & 5.0 & 4.7 & 6.2 & 6.5 & 5.2 & 5.8 & 4.6 \\
\hline $18: 3 \omega 6$ & 0.4 & 0.3 & 0.3 & 0.3 & 0.4 & 0.4 & 0.3 & 0.3 & 0.3 \\
\hline $18: 3 \omega 3$ & 0.4 & 0.4 & 0.3 & $\operatorname{tr}$ & 0.7 & 0.7 & 0.4 & 0.7 & 0.2 \\
\hline $20: 1$ & 2.4 & 2.3 & 3.1 & 3.5 & 2.4 & 2.7 & 2.9 & 2.3 & 2,5 \\
\hline $20: 2 \omega 9$ & 0.5 & 1.1 & 0.9 & 1.1 & 0.6 & 0.6 & 1.0 & 0.7 & 0.6 \\
\hline $20: 3 \omega 9$ & 1.5 & 3.2 & 2.3 & 2.5 & 1.1 & 2.3 & 2.3 & 1.6 & 1.6 \\
\hline $20: 3 \omega 6$ & 5.2 & 2.3 & 3.2 & 3.6 & 4.8 & 4.4 & 4.3 & 3.8 & 3.9 \\
\hline $\left.\begin{array}{l}20: 4 \omega 6 \\
20: 3 \omega 3\end{array}\right\}$ & 8.3 & 7.1 & 5.1 & 5.7 & 9.1 & 8.4 & 7.0 & 5.7 & 6.8 \\
\hline $20: 4 \omega 3$ & $\mathrm{tr}$ & - & 0.5 & 0.2 & 0.2 & 0.7 & 0.4 & 0.4 & 0.1 \\
\hline $20: 5 \omega 3$ & 0.8 & 0.2 & 0.8 & 0.5 & 0.6 & 0.3 & 0.9 & 0.8 & 0.9 \\
\hline $22: 4 \omega 6$ & 1.0 & 0.5 & $\mathrm{tr}$ & 1.3 & 1.0 & 1.0 & 0.5 & 0.5 & 0.5 \\
\hline $22: 5 \omega 6$ & 7.0 & 6.2 & 1.6 & 3.5 & 4.9 & 5.6 & 2.9 & 1.6 & 2.7 \\
\hline $22: 5 \omega^{3}$ & 0.7 & tr & $\mathrm{tr}$ & $\operatorname{tr}$ & 0.6 & 0.6 & 0.6 & 0.7 & 0.6 \\
\hline $22: 6 \omega 3$ & 10.1 & 3.3 & 14.6 & 15.7 & 14.4 & 9.1 & 18.2 & 14.0 & 18.7 \\
\hline $\begin{array}{l}20: 3 \omega 9 / \\
22: 6 \omega 3\end{array}$ & 0.15 & 0.97 & 0.16 & 0.16 & 0.07 & 0.25 & 0.13 & 0.11 & 0.09 \\
\hline$\sum \omega 6$ & 21.1 & 16.5 & 11.6 & 15.0 & 19.0 & 19.7 & 14.9 & 13.3 & 13.3 \\
\hline$\sum \omega 3$ & 12.1 & 4.1 & 16.3 & 16.4 & 16.7 & 11.6 & 20.5 & 16.8 & 20.6 \\
\hline
\end{tabular}

Usually a low EFA diet produces a high concentration of $20: 3 \omega 9$ in polar lipids, but the level of 20:3w9 in the corn oil diet group was not elevated. This agrees with the fact that linoleic acid is effective in reducing the level of the "abnormal" polyunsaturat-

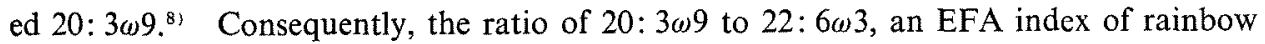
trout, of the fish fed $5 \%$ soybean oil (diet 10 ) appeared as a low value. In addition, in the fish fed diets 14 and 15 in which $0.5 \%$ methyl linolenate was substituted in place of $2 \%$ pollock liver oil, their ratio became 0.07 and 0.25 , respectively. Although both the diets also satisfied EFA requirements for $\omega 3$ fatty acids in diet of rainbow trout, their growth was lower than those receiving the intact pollock liver oil.

Feeding diets containing the pollock liver oil fatty acid fraction (diets 16 and 17) or the methyl esters of soybean oil and of pollock liver oil (diet 18) exerted no appreciable 
effect on fatty acid composition, compared with those of the corresponding fish fed the intact pollock liver oil.

Triglyceride composition Triglyceride composition of the liver lipids in Experiment III was analysed directly by GLC using a short glass column and is presented in Table 11 .

Table 11. Triglyceride compositions of the liver lipids from the fish in Experiment III

\begin{tabular}{|c|c|c|c|c|c|c|c|c|c|}
\hline Triglyceride & 10 & 11 & 12 & 13 & $\begin{array}{c}\text { Diet no. } \\
14\end{array}$ & 15 & 16 & 17 & 18 \\
\hline C34 & $\operatorname{tr}$ & & & $\operatorname{tr}$ & $\operatorname{tr}$ & 0.2 & $\operatorname{tr}$ & $\operatorname{tr}$ & 0.3 \\
\hline $\mathrm{C} 36$ & 0.6 & & & 0.3 & 0.8 & 1.0 & 0.2 & 0.3 & 0.9 \\
\hline $\mathrm{C} 38$ & 0.3 & & & $\mathrm{tr}$ & $\operatorname{tr}$ & 0.5 & $\operatorname{tr}$ & $\operatorname{tr}$ & 0.2 \\
\hline $\mathrm{C} 40$ & $\operatorname{tr}$ & $\operatorname{tr}$ & tr & $\operatorname{tr}$ & tr & $\operatorname{tr}$ & $\operatorname{tr}$ & $\operatorname{tr}$ & $\operatorname{tr}$ \\
\hline $\mathrm{C} 42$ & $\mathrm{tr}$ & $\operatorname{tr}$ & $\operatorname{tr}$ & 0.4 & $\operatorname{tr}$ & $\operatorname{tr}$ & $\operatorname{tr}$ & $\operatorname{tr}$ & 0.5 \\
\hline $\mathrm{C} 44$ & 1.0 & 3.7 & 1.3 & 0.7 & 1.0 & 1.3 & 0.7 & 1.8 & 1.3 \\
\hline $\mathrm{C} 46$ & 3.4 & 4.2 & 4.5 & 3.3 & 3.5 & 3.1 & 3.1 & 2.9 & 4.4 \\
\hline $\mathrm{C} 48$ & 12.1 & 13.9 & 14.4 & 15.1 & 12.4 & 10.9 & 13.1 & 10.3 & 16.3 \\
\hline $\mathrm{C50}$ & 34.3 & 32.5 & 36.0 & 35.2 & 33.4 & 30.6 & 33.7 & 30.8 & 34.1 \\
\hline $\mathrm{C} 52$ & 38.7 & 36.3 & 33.7 & 35.5 & 38.7 & 40.1 & 37.0 & 38.2 & 32.1 \\
\hline C54 & 9.5 & 9.3 & 9.1 & 8.7 & 10.3 & 12.1 & 10.3 & 13.4 & 8.2 \\
\hline $\mathrm{C} 56$ & $\operatorname{tr}$ & $\operatorname{tr}$ & 1.1 & 0.8 & $\operatorname{tr}$ & $\operatorname{tr}$ & 2.0 & 2.3 & 1.5 \\
\hline
\end{tabular}

Rainbow trout showed triglyceride distribution from $C_{34}$ to $C_{56}$ and the dominant components were $\mathrm{C}_{50}$ and $\mathrm{C}_{52}$ triglycerides. As in this experiment fish were fed diets containing almost the same kind of dietary lipids which contained more than $70 \% \mathrm{C}_{18}$ fatty acids, they showed no significant difference in triglyceride composition, and this is also suggested by the result that no appreciable change due to the dietary lipids was recognized in the fatty acid compositions of triglyceride fractions given in Table 9.

A small amount of HUFA in the dietary lipids may not affect triglyceride composition, although $\mathrm{C}_{58}$ triglyceride was detected in fish fed diets containing intact pollock liver oil or its total fatty acid fraction as methyl esters.

Vitamin $\mathbf{A}$ and $\mathbf{E}$ contents Vitamin $\mathrm{A}$ and $\mathrm{E}$ contents in the liver and muscle were determined at the end of feeding trial in Experiment $I$, as shown in Table 12. As already outlined in the previous work with rainbow trout ${ }^{5 /}$ and carp, ${ }^{7)}$ there were some differences in vitamin $\mathrm{A}$ and $\mathrm{E}$ contents which can be explained in terms of dietary lipids. The high vitamin $\mathrm{A}$ value in the fish fed diets containing pollock liver oil evidently

Table 12. Vitamin A and $\alpha$-tocopherol contents in the liver and muscle of rainbow trout in Experiment I

\begin{tabular}{ccccc}
\hline \multirow{2}{*}{ Diet no. } & \multicolumn{2}{c}{ Vitamin A $(\mathrm{IU} / \mathrm{g})$} & & \multicolumn{2}{c}{$\alpha$-Tocopherol $(\mu \mathrm{g} / \mathrm{g})$} \\
\cline { 2 - 5 } \cline { 5 - 5 } & Liver & Muscle & & \multicolumn{2}{c}{ Liver } & Muscle \\
\hline 1 & 12.4 & 1.7 & 962 & 72 \\
2 & 11.7 & 1.1 & 1352 & 91 \\
3 & 38.9 & 2.1 & 1027 & 86 \\
4 & 35.3 & 2.3 & 1046 & 88 \\
\hline
\end{tabular}


reflected the uptake of this vitamin from pollock liver oil and the high $\alpha$-tocopherol content in fish on diet 2 may reflect that of vitamin $E$ from corn oil rich in this vitamin. Both vitamin $\mathrm{A}$ and $\mathrm{E}$ were accumulated in the livers at levels about ten times higher than in the muscle.

The present study has shown that pollock liver oil has a superior food value for growth of rainbow trout and that its fatty acid fraction was the principal element in the nutritive value of pollock liver oil. LEE et al. ${ }^{22)}$ obtained reduced growth when trout were fed corn oil as the sole lipid source but growth increased when linolenate or salmon oil rich in $\mathrm{C}_{20}$ and $\mathrm{C}_{22} \omega 3$ fatty acids were added. $\mathrm{A}$ recent study by CASTELL and

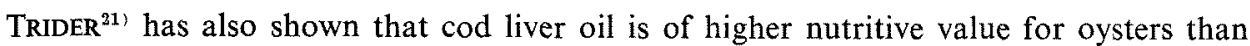
corn oil. These authors suggest that the difference in nutritive value between cod liver oil and corn oil was partly attributable to their fatty acid patterns. Cod liver oil contains high amounts of fatty acids of linolenic series ( $\omega 3$ type), whereas corn oil is characteristically low in linolenic acid. These results support our postulate that the effective components of pollock liver oil which play an important role as EFA in fish are highly unsaturated $\omega 3$ fatty acids such as 20:5 $\omega 3$ and 22: $6 \omega 3$. Moreover, replacing pollock liver oil with a comparable amount of methyl linolenate did not improve fish growth over that realized with the diets containing pollock liver oil, and this indicates that HUFA may have a higher EFA value than that of linolenic acid in a manner similar to the relationship existing between linoleic and arachidonic acids in mammals. ${ }^{23)}$ It

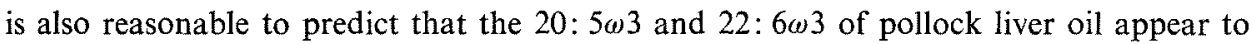
act in enhancing fish growth, and that a blance of proportions of component fatty acids of these types in natural lipids is more important for growth of fish than is the total amount of $\omega 3$ fatty acids in diet.

In this study the effect of phospholipids on growth of fish was examined using lecithin, although there is no direct comparison as the pollock liver oil which contained only a trace amount of polar lipids. The addition of lecithin to methyl laurate at the level of 0.01 and $0.05 \%$ did not result in any improvement in growth conditions. This suggests that an additive effect of phospholipids is obtained only when they are supplemented to a diet with sufficient amounts of EFA.

Growth effect or additive effect of the nonsaponifiable fraction, which contains fatsoluble vitamins, were not recognized in Experiment II of feeding for 8 weeks, indicating that basal diet used contained sufficient amounts of fat-soluble vitamins for growth of rainbow trout, although an additive effect of the nonsaponifiable fraction was detectable in the long term in fish growth. This result concurrs well with the report by YoNE et al. ${ }^{19}$ ? that residual pollock liver oil after molecular distillation for vitamins is better for improving growth of red sea bream than corn oil or soybean oil. 


\section{Acknowledgements}

We express here our sincere thanks to Dr. Yoshiro Hashimoro, Professor, Faculty of Agriculture, the University of Tokyo, Dr. R. G. Ackman and Dr. J. D. Castell, Department of Environment, Fisheries and Marine Service, Halifax Laboratory, and Dr. Chinkichi Ogino, Professor, Tokyo University of Fisheries, who kindly read the manuscript and gave valuable suggestions. Thanks are also due to Dr. Yasuo Yone, Professor, Faculty of Agriculture, Kyushu University and the Riken Vitamin Oils Co. Ltd, who kindly provided HUFA and the purified pollock liver oil, respectively.

\section{References}

1) J. D. Castell, R. O. Sinnhuber, J. H. Wales, and D. J. Lee: J. Nutrition, 102, 77-86 (1972).

2) J. D. Castell, R. O. Sinnhuber, D. J. Lee, and J. H. Wales: ibid., 102, 87-92 (1972).

3) J. D. Castell, D. J. Lee, and R. O. Sinnhuber: ibid, 102, 93-100 (1972).

4) T. Watanabe, F. Takashima, and C. Ogino: This Bull., 40, 181-188 (1974).

5) T. Watanabe, I. Kobayashi, O. Utsue, and C. Ogino: ibid., 40, 387-392 (1974).

6) T. Watanabe, C. Ogino, Y. Koshishi, and T. Matsunaga: ibid., 40, $493-499$ (1974).

7) T. Watanabe, O. Utsue, I. Kobayashi, and C. Ogino: ibid., 41, 257--262 (1975).

8) T. Watanabe, T. Takeuchi, and C. Ogino: ibid., 41, 263-269 (1975).

9) Y. YoNe and M. FuJI: ibid., 41, 73-77 (1975).

10) Y. YONE and M. FuJn: ibid., 41, 79-86 (1975).

11) T. Honjo: Aquaculture, 13, 15-21 (1965).

12) A. M. Phillips, Jr., D. L. Livingston, and H. A. Poston: Prog. Fish-Cult., 25, 8-14 (1963).

13) H. Higashi, T. KaneKo, S. Ishit, M. UChIYAma, and T. Sugihashi: J. Vitaminology, 30, 271275 (1964).

14) T. Kaneko, M. Takeuchi, S. Ishi, H. Higashi, and T. Kikuch: This Bull., 33, 47-55 (1967).

15) T. C. YU and R. O. Sinnhuber: Lipids, 1, 450-454 (1972).

16) L. P. MetCalf and A. A. Schmitz: Anal. Chem., 32, 363-365 (1961).

17) T. Watanabe, F. Takashima, C. Ogino, and T. Hibiya: This Bull., 36, 623-630 (1970).

18) S. ARaI, T. Nose, and Y. Hashimoto: Bull. Freshwater Fish. Res. Lab., 21, 161-178 (1971).

19) Y. Yone, M. Furticht, and S. Sakamoto: Report Fish. Res. Lab., Kyusu Univ., No. 1, 49-60 (1971).

20) H. Tsukahara, A. Furukawa, and K. Funae: Bull. Naikai Reg. Fish. Res. Lab., No. 24, 29-50 (1967).

21) J. D. CAstell and D. J. Trider: J. Fish. Res. Bd. Canada, 31, 95-99 (1974).

22) D. J. Lee, J. N. Roehm, T. C. Yu, and R. O. Sinnhuber: J. Nutrition, 92, 93-98 (1967).

23) R. B. Alfin-Slater and T. Kaneda: Federation Proc., 21, 285 (1962). 